\title{
Characterisation of the leukotoxin produced by different strains of Pasteurella haemolytica
}

\author{
M. SAADATI, H. A. GIBBS*, R. PARTON and J. G. COOTE \\ Division of Infection and Immunity and *Department of Veterinary Medicine, University of Glasgow, Glasgow \\ G12 800
}

\begin{abstract}
Pasteurella haemolytica isolates from cattle and sheep, including representatives of different serotypes and untypable strains, were examined for leukotoxin (Lkt) production at the end of the log phase of growth in brain heart infusion broth. There were marked differences in leukotoxic activity in culture supernate samples, as measured by chemiluminescence-inhibition assays with bovine and ovine neutrophils, even between strains of the same serotype. There was also some variation in the amount and mol.wt of the Lkt protein produced by different strains, as judged by SDS-PAGE, immunoblotting and ELISA. Some strains produced normal amounts of Lkt protein which had only low leukotoxic activity. Most strains produced Lkt of $105 \mathrm{kDa}$ whereas four strains produced a higher mol.wt form of $c .108 \mathrm{kDa}$, including two of the five serotype A2 strains examined. Thus, the $P$. haemolytica isolates showed considerable heterogeneity in terms of leukotoxin production, mol. wt and activity, even within a given serotype.
\end{abstract}

\section{Introduction}

Pasteurella haemolytica is responsible for economically important diseases of ruminants including pneumonic pasteurellosis of cattle and sheep $[1,2]$. The species comprises two biotypes, A and T, although it has been proposed that biotype $\mathrm{T}$ be renamed $P$. trehalosi [3]. $P$. haemolytica of various serotypes and in low numbers is part of the normal flora of the upper respiratory tract of healthy animals. Under conditions of stress due to management and environmental factors or other infectious agents, where lung clearance mechanisms are impaired, the lungs become colonised by the organism and disease ensues. Whereas Al is the predominant serotype isolated from cattle with pneumonic pasteurellosis, A2 predominates in cases in sheep. Biotype $\mathrm{T}(P$. trehalosi $)$ strains cause a pathologically distinct systemic infection of young adult sheep. Approximately $10 \%$ of all isolates from cattle and sheep are untypable by the usual method of indirect haemagglutination.

Current vaccines against pneumonic pasteurellosis, including live or killed bacteria or various cell components, do not seem to provide consistent protection. $P$. haemolytica produces various virulence

Received 22 Aug. 1996; accepted 12 Sept. 1996. Corresponding author: Dr J. G. Coote. components that are potential protective antigens. These include leukotoxin (Lkt), lipopolysaccharide (LPS), capsular polysaccharides, fimbriae and various outer-membrane proteins (OMP) [4]. Lkt in particular has attracted much interest as a vaccine component as it is thought to play a central role in the disease process. A naturally occurring antibody response to Lkt has been correlated to disease resistance in the field, and vaccines containing Lkt, along with other components, give some protection against experimental challenge. However, an immune response to Lkt alone does not appear to be sufficient to protect animals from disease [5].

Lkt is one of a group of high mol.wt, calciumdependent, pore-forming protein toxins produced by several gram-negative bacteria. These toxins show structural, antigenic and genetic homology with the widely studied haemolysin of Escherichia coli. They have been designated the RTX (repeats in toxin) family due to the presence of characteristic glycinerich repeat units at their C-termini [6]. They also have similar mechanisms for their activation and secretion from the bacterial cell. For example, active Lkt is produced as an inactive precursor, the product of the $l k t A$ gene, and is then activated post-translationally by the $l k t C$ gene product. The apparent mol. wt of $\mathrm{Lkt}$, as estimated from SDS-PAGE and immunoblotting, is $c$. $105 \mathrm{kDa}$ [7], which is similar to the $102 \mathrm{kDa}$ predicted from the nucleotide sequence of the $l k t A$ gene [8]. 
The RTX toxins vary in their target cell specificity. Some are cytotoxic for a wide variety of eukaryotic cell types whilst others are more specific. Lkt has been reported to act predominantly on leucocytes of ruminant species [9], which thus parallels the susceptibility of ruminants, and the low susceptibility of non-ruminants, to $P$. haemolytica infection. Both lytic and non-lytic effects have been reported. These various effects on leucocytes, resulting in impairment of host defences and release of lysosomal contents and toxic oxygen radicals, are thought to be important in the harmful inflammatory reactions and lung damage of pneumonic pasteurellosis [10]. One of the effects of Lkt on neutrophils in vitro is the suppression of their respiratory burst in response to stimuli such as opsonised zymosan. This can be measured as inhibition of a chemiluminescence response and provides a sensitive and convenient assay for the toxin $[11,12]$.

The aim of the present investigation was to further an understanding of the role of Lkt in the pathogenesis and immunity of pneumonic pasteurellosis. In recent work from this laboratory, analysis of outer-membrane protein and lipopolysaccharide profiles of a large number of $P$. haemolytica isolates by electrophoresis and immunoblotting has shown that there is considerable inter-strain variation within the existing serotype groupings [13-15]. In the present study, a similar number of $P$. haemolytica isolates, including representatives of all serotypes and untypable strains, was examined for Lkt production.

\section{Materials and methods}

\section{Bacteria}

Many of the strains have been used in previous studies in this laboratory [13, 16-18] and a brief description of some of their important characteristics is given in Table 1. Strains prefixed with $\mathrm{Ph}$ (except 142, 252 and 706) were collected from various parts of Scotland, from pneumonic and healthy cattle, over the period 1982-85. Strains with five-number designations (10632, etc.), were NCTC strains and all were ovine isolates. The remainder were a mixture of ovine and bovine isolates from the collection of $\mathrm{Dr} \mathrm{W}$. Donachie, Moredun Research Institute, Edinburgh.

Table 1. Characteristics of strains used in this study

\begin{tabular}{|c|c|c|c|c|c|c|c|}
\hline \multirow{2}{*}{$\begin{array}{l}\text { Laboratory } \\
\text { designation }\end{array}$} & \multirow[b]{2}{*}{ Serotype } & \multirow{2}{*}{$\begin{array}{l}\text { Species } \\
\text { of origin }\end{array}$} & \multirow[b]{2}{*}{ Isolation } & \multirow{2}{*}{$\begin{array}{l}\text { Disease status } \\
\text { of host }\end{array}$} & \multirow{2}{*}{$\begin{array}{l}\text { Age of } \\
\text { culture } \\
(\mathrm{h})^{*}\end{array}$} & \multicolumn{2}{|c|}{$\begin{array}{l}\text { Leukotoxic activity: percentage } \\
\text { inhibition of } \mathrm{CL} \text { response } \\
\text { of neutrophils } \dagger \text { (SD) }\end{array}$} \\
\hline & & & & & & Bovine & Ovine \\
\hline Ph 2 & A1 & Bovine & LRT & Pneumonic & 6.0 & $97(0.2)$ & $97(0.5)$ \\
\hline $\mathrm{Ph} 10$ & Al & Bovine & LRT & Pneumonic & 6.0 & $95(0.6)$ & $96(0.3)$ \\
\hline $\mathrm{Ph} 12$ & $\mathrm{~A} 1$ & Bovine & LRT & Pneumonic & 8.0 & $83(2.4)$ & $90(0.7)$ \\
\hline $\mathrm{Ph} 14$ & Al & Bovine & LRT & Pneumonic & 8.0 & $6(0.6)$ & $20(2.7)$ \\
\hline $\mathrm{Ph} 26$ & A1 & Bovine & NP & Healthy & 8.0 & $84(1.6)$ & $90(0.4)$ \\
\hline $\mathrm{Ph} 30$ & Al & Bovine & NP & Healthy & 5.3 & $50(0.4)$ & $75(1.5)$ \\
\hline $\mathrm{Ph} 6$ & $\mathrm{Al}$ & Bovine & NP & Healthy & 6.0 & $0(0.1)$ & $0(0.1)$ \\
\hline V965B & $\mathrm{Al}$ & Ovine & Lung & Pneumonic & 6.0 & $67(1.6)$ & $89(0.6)$ \\
\hline FA 1 & A1 & Ovine & Lung & Pneumonic & 7.3 & $78(1.0)$ & $85(0.9)$ \\
\hline $\mathrm{Ph} 42$ & $\mathrm{~A} 2$ & Bovine & Lung & Pneumonic & 8.0 & $6(1.2)$ & $26(1.5)$ \\
\hline $\mathrm{Ph} 44$ & $\mathrm{~A} 2$ & Bovine & NP & Healthy & 8.3 & $42(1.1)$ & $56(2.7)$ \\
\hline B664 & $\mathrm{A} 2$ & Ovine & Lung & Pneumonic & 8.0 & $5(2.0)$ & $22(1.7)$ \\
\hline T884 & $\mathrm{A} 2$ & Ovine & Lung & Pneumonic & 8.0 & $61(2.5)$ & $85(0.8)$ \\
\hline $\mathrm{Ph} 142$ & $\mathrm{~A} 2$ & Ovine & Lung & Pneumonic & 8.0 & $18(1.8)$ & $85(0.5)$ \\
\hline 10630 & A5 & Ovine & Lung & Pneumonic & 6.3 & $95(0.6)$ & $97(0.2)$ \\
\hline 10632 & A6 & Ovine & Lung & Pneumonic & 6.3 & $94(0.8)$ & $95(0.4)$ \\
\hline 10634 & $\mathrm{~A} 7$ & Ovine & Lung & Pneumonic & 6.3 & $95(0.4)$ & $95(0.4)$ \\
\hline 10636 & A8 & Ovine & Lung & Pneumonic & 7.0 & $93(0.3)$ & $94(0.3)$ \\
\hline 10639 & A9 & Ovine & Lung & Pneumonic & 6.3 & $96(0.2)$ & $97(0.4)$ \\
\hline 10642 & A11 & Ovine & NP & Healthy & 5.0 & $45(1.2)$ & $60(2.6)$ \\
\hline 10644 & A12 & Ovine & NP & Healthy & 4.3 & $90(0.4)$ & $92(0.9)$ \\
\hline 11302 & A13 & Ovine & Lung & Pneumonic & 6.3 & $91(0.4)$ & $94(0.4)$ \\
\hline 10640 & A13 & Ovine & NP & Healthy & 5.3 & $90(0.3)$ & $90(0.5)$ \\
\hline 11303 & A14 & Ovine & Lung & Pneumonic & 5.3 & $91(0.6)$ & $94(0.7)$ \\
\hline $\mathrm{Ph} 706$ & A16 & Ovine & $\mathrm{n} / \mathrm{k}$ & $\mathrm{n} / \mathrm{k}$ & 6.0 & $92(0.5)$ & $94(0.6)$ \\
\hline FT 3 & T3 & Ovine & NP & $\mathrm{n} / \mathrm{k}$ & 6.0 & $15(2.1)$ & $32(2.0)$ \\
\hline FT 4 & $\mathrm{~T} 4$ & Ovine & Lung & Pneumonic & 4.3 & $36(1.1)$ & $40(1.6)$ \\
\hline $\mathrm{Ph} 252$ & $\mathrm{~T} 10$ & Ovine & $\mathrm{n} / \mathrm{k}$ & $\mathrm{n} / \mathrm{k}$ & 4.3 & $20(1.0)$ & $35(0.9)$ \\
\hline 10641 & $\mathrm{~T} 15$ & Ovine & Liver/spleen & $\mathrm{n} / \mathrm{k}$ & 4.3 & $25(1.7)$ & $39(2.4)$ \\
\hline UT 2 & UT & Bovine & Lung & Pneumonic & 3.3 & $75(0.4)$ & $82(0.5)$ \\
\hline UT 3 & UT & Bovine & Lung & Pneumonic & 5.3 & 100 & 100 \\
\hline UT 23 & UT & Bovine & Lung & Pneumonic & 4.3 & $30(1.0)$ & $39(0.6)$ \\
\hline UT 27 & UT & Bovine & Lung & Pneumonic & 5.0 & $83(3.9)$ & $85(0.9)$ \\
\hline
\end{tabular}

UT, untypable; LRT, lower respiratory tract; NP, nasopharynx; $\mathrm{n} / \mathrm{k}$, not known.

${ }^{*}$ Time of harvest of culture (end of log phase) for assay of Lkt in culture supernate.

†Percentage inhibition of the normal CL response of neutrophils to opsonised zymosan (OZ). Neutrophils were incubated with culture supernate samples for $30 \mathrm{~min}$ at $37^{\circ} \mathrm{C}$ before addition of $\mathrm{OZ}$. Results are mean values from five independent assays. 
Stock cultures were stored at $-70^{\circ} \mathrm{C}$ in Brain Heart Infusion Broth (BHIB; Oxoid) containing glycerol $50 \% \mathrm{v} / \mathrm{v}$. The bacteria were grown routinely in BHIB or on BHI agar (BHIA; Oxoid) containing defibrinated sheep blood $5 \% \mathrm{v} / \mathrm{v}$ and incubated overnight at $37^{\circ} \mathrm{C}$. All strains were characterised by the API $20 \mathrm{NE}$ assay (API) and the serotypes of the A1, A2 and T strains were confirmed by indirect haemagglutination [19] with type-specific sera kindly provided by $\mathrm{Dr}$ W. Donachie.

\section{Preparation of leukotoxin}

Culture supernates, as a source of leukotoxin, were prepared from different isolates at different times during growth. Bacteria from overnight BHIB cultures at $37^{\circ} \mathrm{C}$ were washed and suspended in PBS. They were adjusted to an optical density of 0.4 at $640 \mathrm{~nm}$ and 1$\mathrm{ml}$ volumes were inoculated into $50-\mathrm{ml}$ volumes of BHIB in 250-ml conical shake flasks and incubated at $37^{\circ} \mathrm{C}$ and $120 \mathrm{rpm}$. Changes in optical density were monitored and, at intervals, cultures were centrifuged at $7000 \mathrm{~g}$ for $10 \mathrm{~min}$ at $4^{\circ} \mathrm{C}$. The resulting supernates were passed through $0.45-\mu \mathrm{m}$ membrane filters (Acrodisc; Gelman Sciences) and stored at $-70^{\circ} \mathrm{C}$.

For preparation of leukotoxin under different conditions of aeration, the growth conditions of Davies et al. [18] were used (i.e., very high aeration, high aeration, moderate aeration, low aeration, no aeration and $\mathrm{CO}_{2}$ atmosphere).

\section{Chemiluminescence (CL) assay}

Heparinised blood was obtained from healthy calves and sheep. For preparation of neutrophils, 10-ml volumes of blood were diluted with equal volumes of PBS ( $\mathrm{pH} \mathrm{7.38)} \mathrm{and} \mathrm{carefully} \mathrm{layered} \mathrm{on} \mathrm{top} \mathrm{of} 5 \mathrm{ml}$ of Histopaque (Sigma) at a density of $1.077 \mathrm{~g} / \mathrm{ml}$ and centrifuged at $830 \mathrm{~g}$ for $30 \mathrm{~min}$ at room temperature. The supernatant layers containing plasma, mononuclear cells and Histopaque were aspirated. For lysis of the red blood cells, the pellet was suspended in 3 volumes of ice-cold $\mathrm{NH}_{4} \mathrm{Cl}$ medium $\left(155 \mathrm{mM} \mathrm{NH}_{4} \mathrm{Cl}, 10 \mathrm{mM}\right.$ $\mathrm{KHCO}_{3}, 0.1 \mathrm{mM}$ EDTA). After 5-7 min, the colour of the cell suspension changed from red to black indicating lysis of the erythrocytes. The suspension was then centrifuged at $400 \mathrm{~g}$ for $5 \mathrm{~min}$ at $4^{\circ} \mathrm{C}$. The lysis procedure was repeated and the remaining cells were washed twice with PBS and finally suspended in Hanks's HEPES $(\mathrm{HH})$, containing $(\mathrm{g} / \mathrm{L}): \mathrm{NaCl}, 8 ; \mathrm{KCl}$, $0.4 ; \mathrm{CaCl}_{2} .6 \mathrm{H}_{2} \mathrm{O}, 0.19 ; \mathrm{MgCl}_{2} .6 \mathrm{H}_{2} \mathrm{O}, 0.2$; glucose, 1 ; HEPES 2.3, pH 7.38. The resulting cell suspension was $>95 \%$ neutrophils, and neutrophil viability, determined by trypan blue dye $0.1 \% \mathrm{w} / \mathrm{v}$ exclusion, was $>98 \%$ in all preparations examined.

For preparation of opsonised zymosan (OZ), $100 \mathrm{mg}$ of zymosan A (Sigma; from Saccharomyces cerevisiae) was added to $5 \mathrm{ml}$ of normal bovine serum $10 \% \mathrm{v} / \mathrm{v}$ in PBS, and this mixture was incubated at $37^{\circ} \mathrm{C}$ for $30 \mathrm{~min}$ with shaking at $30 \mathrm{rpm}$. The $\mathrm{OZ}$ was washed twice with ice-cold $\mathrm{PBS}, \mathrm{pH} 7.38$, and finally suspended in $10 \mathrm{ml}$ of PBS and stored at $-20^{\circ} \mathrm{C}$ until used.

DNDH (7-dimethylamino-naphthalene-1, 2 dicarbonic acid hydrazide; Boerhinger), was prepared as a $0.01 \mathrm{M}$ stock solution in dimethyl sulphoxide. The working dilution $(0.0001 \mathrm{M})$ was prepared in $\mathrm{HH}$.

For the routine CL assay $15 \mu 1$ of culture supernate containing leukotoxin were added to $885 \mu \mathrm{l}$ of $\mathrm{HH}$ containing neutrophils and DNDH and incubated for $30 \mathrm{~min}$ at $38^{\circ} \mathrm{C}$. Neutrophils were then stimulated with $100 \mu \mathrm{l}$ of $\mathrm{OZ}$ and the resulting $\mathrm{CL}$ was measured with a Wallac luminometer connected to an IBM-pc computer with Multi-Use software (Bio-Orbit, Turku, Finland). The $\mathrm{CL}$ emission was measured in millivolts $(\mathrm{mV})$ at $38^{\circ} \mathrm{C}$. Each sample was tested in duplicate, and contained neutrophils $\left(5 \times 10^{5}\right)$, DNDH $\left(10^{-5} \mathrm{M}\right)$, $\mathrm{OZ}(0.5 \mathrm{mg}), \mathrm{HH}(\mathrm{pH} 7.38)$ in a final volume of $1 \mathrm{ml}$. Results for leukotoxic activity are expressed as percentage inhibition of the peak value of the normal $\mathrm{CL}$ response of the neutrophils to $\mathrm{OZ}$ and are mean values from five independent assays.

\section{Antibody preparation}

For preparation of rabbit antibody to Lkt, recombinant Lkt (rLkt) expressed in $E$. coli and partially purified from insoluble inclusion bodies (G. D. Westrop et al., unpublished report) was resolved by SDS-PAGE with acrylamide gel $7.5 \% \mathrm{w} / \mathrm{v}$. The gel was stained with Coomassie Blue R $2500.1 \% \mathrm{w} / \mathrm{v}$ for $5 \mathrm{~min}$ and then destained for $20 \mathrm{~min}$. The band at $105 \mathrm{kDa}$ was excised carefully, washed in sterile PBS, crushed, suspended in sterile PBS and dialysed at $4^{\circ} \mathrm{C}$ for $18 \mathrm{~h}$ against saline. The supernate from the dialysis sac was emulsified in an equal volume of Freund's incomplete adjuvant (Sigma). A female New Zealand White rabbit was inoculated intramuscularly with a total volume of $2 \mathrm{ml}$. Before injection of sample, the rabbit was bled for preimmune serum. The final antiserum was collected 1 week after the rabbit had received four booster injections at monthly intervals.

Mouse hybridoma culture supernate containing monoclonal antibody (MAb) raised against rLkt from $E$. coli was kindly provided by Dr W. Donachie.

\section{Analytical SDS-PAGE and immunoblotting}

SDS-PAGE was done according to the method of Laemmli [20] in a vertical slab gel apparatus (Protean II; BioRad). Stacking gels and resolving gels contained acrylamide at $4 \% \mathrm{w} / \mathrm{v}$ and $10 \% \mathrm{w} / \mathrm{v}$, respectively. Samples were solubilised in an equal volume of sample buffer and heated in a water bath at $100^{\circ} \mathrm{C}$ for $5 \mathrm{~min}$. After SDS-PAGE, the resolved protein bands were transferred to a nitrocellulose membrane (Hybond-C 
super, Amersham) by the method of Towbin et al. [21] in a BioRad transblot cell. Blots were probed with $\mathrm{MAb}$ to $\mathrm{rLkt}$ followed by anti-mouse IgG-HRP conjugate (Scottish Antibody Production Unit: SAPU).

\section{ELISA}

The wells of flat-bottomed, microtitration plates (Dynatech Immulon ${ }^{\mathrm{TM}}$ ) were coated with $350 \mu \mathrm{l}$ of MAb to rLkt diluted 1 in 100 in $0.05 \mathrm{M}$ carbonate buffer, $\mathrm{pH}$ 9.6. The plates were incubated at $4^{\circ} \mathrm{C}$ overnight in a humidified box then washed three times with washing buffer containing gelatin $0.5 \% \mathrm{w} / \mathrm{v}$ and Tween $200.01 \% \mathrm{v} / \mathrm{v}$ in PBS, $\mathrm{pH}$ 7.4. Culture supernate samples or rLkt were diluted in washing buffer and $300 \mu \mathrm{l}$ were added to the wells. The plates were incubated for $2 \mathrm{~h}$ at $37^{\circ} \mathrm{C}$ in a humidified box and then washed as above. To each well, $250 \mu \mathrm{l}$ of rabbit polyclonal antibody raised against $\mathrm{rLkt}$, at a dilution of 1 in 3000 in washing buffer, were added. The plates were incubated for $4 \mathrm{~h}$ at $37^{\circ} \mathrm{C}$ in a humidified box, washed, and $250 \mu \mathrm{l}$ of anti-rabbit IgG-HRP conjugate (SAPU) diluted 1 in 3000 in washing buffer were added to each well and the plate was incubated overnight at $4{ }^{\circ} \mathrm{C}$ and washed as above. The enzyme reaction was initiated by the addition of $200 \mu \mathrm{l}$ of $o$ phenylenediamine $\left(34 \mathrm{mg} / \mathrm{ml}\right.$; Sigma) and $\mathrm{H}_{2} \mathrm{O}_{2}$ $(20 \mu \mathrm{l})$ in $100 \mathrm{ml}$ of $0.15 \mathrm{M}$ citrate-phosphate buffer, $\mathrm{pH} 5.0$ (freshly prepared). The plate was incubated for $30 \mathrm{~min}$ at room temperature in the dark for colour development. The reaction was stopped by addition of $50 \mu \mathrm{l}$ of $\mathrm{H}_{2} \mathrm{SO}_{4} \quad 12.5 \% \mathrm{v} / \mathrm{v}$ to each well. Absorbance was measured at $492 \mathrm{~nm}$ in an Anthos 2001 ELISA reader. As a reference preparation, a culture supernate from strain $\mathrm{Ph} 2$, was included in each plate. This was assigned an arbitrary value of $100 \mathrm{Lkt}$ units $/ \mathrm{ml}$. The Lkt antigen content of other samples was calculated with a parallel line assay by comparison of absorbance values for the reference and test samples.

\section{Protein estimation}

Protein content was estimated by the method of Bradford [22] with bovine serum albumin (Sigma) as a standard.

\section{Results}

\section{Optimum conditions for Lkt production}

Thirty-three $P$. haemolytica isolates, including representatives of all different serotypes and some untypable strains, were examined for Lkt production in culture supernates. In initial experiments, optimal conditions for growth and Lkt production in BHIB were determined. Growth of strains $\mathrm{Ph} 2$ and $\mathrm{Ph} 30$ under various conditions was monitored by spectrophotometry. Lkt production was judged by SDS-PAGE and immunoblotting of culture supernate samples, and Lkt activity was measured by the CL-inhibition assay.
When different conditions of aeration of the culture (i.e., very high aeration, high aeration, moderate aeration, low aeration, no aeration and $\mathrm{CO}_{2} \quad 5 \%$ atmosphere [18]) were examined, the maximum yield of toxin and growth was obtained with very high aeration, i.e., $50 \mathrm{ml}$ of culture in a $250-\mathrm{ml}$ dimpledshake flask shaken at $120 \mathrm{rpm}$. With different temperatures $\left(25^{\circ}, 30^{\circ}, 35^{\circ}, 37^{\circ}, 40^{\circ}\right.$ and $\left.43^{\circ} \mathrm{C}\right)$ of incubation, $P$. haemolytica produced most toxin and grew optimally at $37^{\circ} \mathrm{C}$.

The age of the culture had a major influence on Lkt yield, as judged by immunoblotting of culture supernate samples, and on Lkt activity, as measured by CLinhibition with bovine neutrophils. As shown in Fig. 1, Lkt activity of strain $\mathrm{Ph} 2$ growing in BHIB closely paralleled bacterial growth, with a maximum at the end of $\log$ phase. As the culture aged, there was a decline in toxin activity. Similar results were obtained with other P. haemolytica strains. Thus, in comparing Lkt activity of different strains of $P$. haemolytica, bacteria were grown in BHIB at $37^{\circ} \mathrm{C}$ with very high aeration and culture supernates were sampled at different times to include the end of $\log$ phase. The timing of this point of the growth curve varied somewhat from strain to strain (Table 1). Culture supernate samples containing Lkt showed a reduction in toxic activity on standing at room temperature or at $4^{\circ} \mathrm{C}$ and, to a lesser extent, even on prolonged storage at $-70^{\circ} \mathrm{C}$. Thus for comparative purposes, all preparations were tested immediately after harvest and a culture supernate sample from strain $\mathrm{Ph} 2$ was used as control and internal standard in every assay.

\section{CL inhibition by Lkt preparations}

Results of a typical CL-inhibition assay, with bovine neutrophils and samples from three strains of $P$. haemolytica, are shown in Fig. 2. The culture supernate of strain $\mathrm{Ph} 2$ was highly toxic and caused almost complete inhibition of $\mathrm{CL}$, that from strain $\mathrm{Ph} 30$ caused about $50 \%$ inhibition whereas that from strain B644 had little effect. Overall, culture supernate samples from most strains (21 of 33) were highly toxic (i.e., caused $>80 \%$ inhibition of the normal $\mathrm{CL}$ response) for bovine or ovine neutrophils, or both (Table 1). Samples from an untypable strain UT 3 proved to be the most toxic and gave $100 \%$ inhibition of $\mathrm{CL}$ even when diluted 1 in 5 . Three strains were moderately toxic $(41-80 \%$ inhibition) for bovine or ovine neutrophils, or both. Eight strains had low toxicity $(<40 \%$ inhibition) for both bovine and ovine neutrophils; these included one serotype A1, two A2, four biotype $\mathrm{T}$ ( $P$. trehalosi) and one untypable strain. Only one strain, $\mathrm{Ph} 6$, a bovine isolate of serotype $\mathrm{Al}$, produced no detectable toxic activity. With all strains, culture supernate samples taken earlier or later during growth did not show any greater toxic activity. Serial passage of $P$. haemolytica strains $\mathrm{Ph} 2$ and $\mathrm{Ph} 10$, up to 40 times, had no effect on the activity of Lkt produced. 


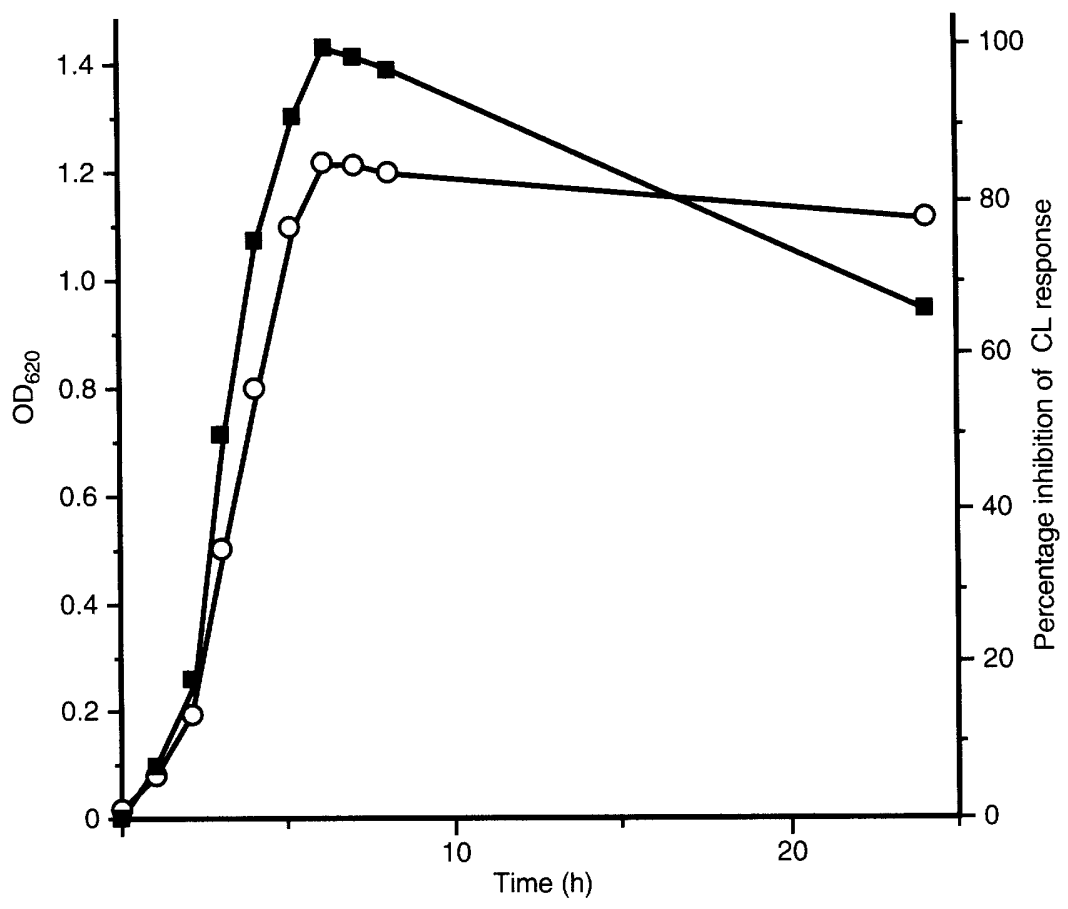

Fig. 1. Lkt activity (- - ) in the culture supernate during growth (-O-) of $P$. haemolytica strain $\mathrm{Ph} 2$ in BHIB. Lkt activity was measured by its inhibition of the normal CL response of bovine neutrophils to $\mathrm{OZ}$.

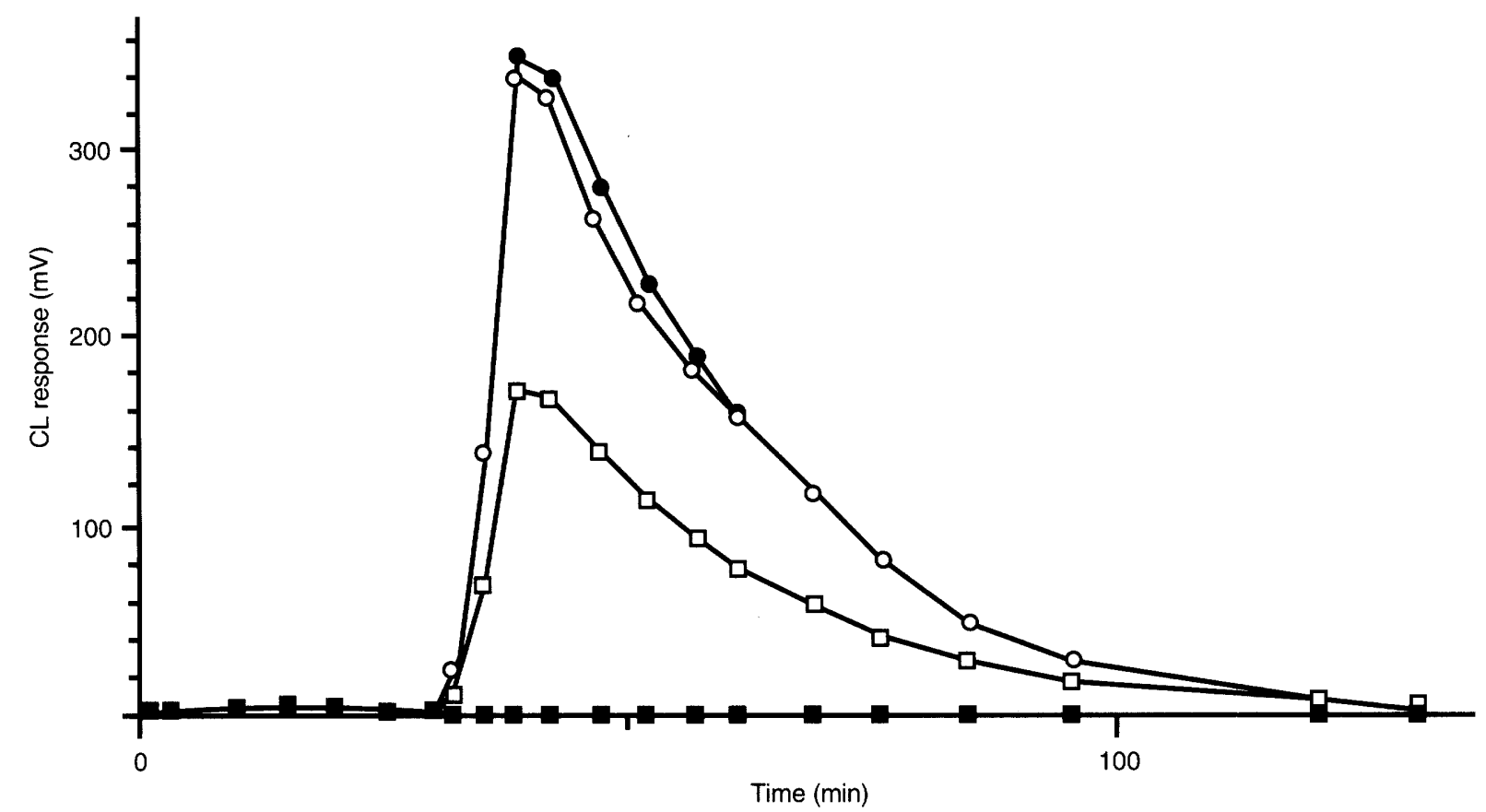

Fig. 2. The effect of culture supernates from different strains of $P$. haemolytica on the CL response of bovine neutrophils to OZ: - - , control CL response (no culture supernate added); $-\mathbf{-}-$, CL response of neutrophils treated with culture supernate from strain $\mathrm{Ph} 2 ;-\square-$, strain $\mathrm{Ph} 30 ;-\mathrm{O}-$, strain B664.

By analysis of variance according to the general linear model (Minitab), the Lkt preparations from bovine isolates were, overall, significantly less toxic for neutrophils, as shown by inhibition of the normal $\mathrm{CL}$ response, than Lkt preparations from ovine isolates $(\mathrm{p}=0.018)$. The mean percentage inhibition of CL was $61.91(\mathrm{SEM}=3.04, \mathrm{n}=130)$ for bovine preparations and $70.36(\mathrm{SEM}=2.11, \mathrm{n}=200)$ for ovine preparations. Ovine neutrophils were significantly $(\mathrm{p}=0.009)$ more sensitive to the Lkt preparations than bovine neutrophils. The mean percentage inhibition of $\mathrm{CL}$ was $71.86(\mathrm{SEM}=2.27, \mathrm{n}=165)$ for ovine and 62.2 $(\mathrm{SEM}=2.66, \mathrm{n}=165)$ for bovine neutrophils.

\section{Specificity of the CL assay for $L k t$}

The specificity of the $\mathrm{CL}$ assay for Lkt was tested in various ways. 
Culture supernate samples from $P$. multocida NCTC10322, presumably containing cell products common to Pasteurella spp., caused no inhibition of the $\mathrm{CL}$ response of bovine neutrophils to $\mathrm{OZ}$.

Active rLkt, produced from the cloned $l k t A$ and $l k t C$ genes co-expressed in E. coli (G. D. Westrop et al., unpublished report) completely inhibited the CL response of bovine neutrophils whereas non-activated $\mathrm{Lkt}$, produced in the absence of $\mathrm{LktC}$, had no effect. The rLkt preparations were tested at the same protein concentrations $(3.5-35 \mu \mathrm{g} / \mathrm{ml})$ and the active and nonactivated rLkt preparations contained similar amounts of Lkt antigen as judged by immunoblotting and ELISA.

P. haemolytica produces LPS in the culture supernate, as shown by Western blotting with rabbit polyclonal serum raised against LPS. To test the possibility that the toxicity of culture supernates for neutrophils was due to, or affected by, contaminating LPS, additional studies were done. CL inhibitory activity was destroyed by boiling for $30 \mathrm{~min}$ (LPS is heat stable and would be expected to withstand this treatment). In addition, purified LPS (rough and smooth) from $P$. haemolytica A1 and LPS from smooth $E$. coli (kindly provided by $\mathrm{Dr} \mathrm{R}$. Davies) at concentrations up to $40 \mu \mathrm{g} / \mathrm{ml}$ had no significant inhibitory effect on the $\mathrm{CL}$ response of bovine neutrophils and did not kill the cells.

Finally, the CL-inhibitory activity was shown to be neutralised by antibody specific for Lkt. Culture supernates of $P$. haemolytica $\mathrm{Ph} 2$ (undiluted) and active rLkt ( 1 in 1000 dilution) from $E$. coli were incubated for $30 \mathrm{~min}$ with polyclonal antiserum raised against purified rLkt and their toxicity was then measured in the CL assay. The antiserum completely inhibited the effect of both preparations of Lkt on the neutrophils.
Variation in amount and mol.wt of Lkt produced by different strains of $P$. haemolytica

All isolates produced Lkt in culture supernates, except $\mathrm{Ph} 6$ which did not produce Lkt as judged by SDSPAGE and immunoblotting with MAb. There was some variation in the mol. wt of Lkt produced by different strains of $P$. haemolytica. Most isolates (28 of 32) produced Lkt of c. $105 \mathrm{kDa}$, as shown in lanes 1, 3, 5, 7 and 9 (Fig. 3). Four strains ( $\mathrm{Ph} \mathrm{42,} \mathrm{Ph} \mathrm{44,} \mathrm{10634,} \mathrm{UT}$ 23; lanes 2, 4, 6 and 8, respectively) produced Lkt of $c$. $108 \mathrm{kDa}$.

Fig. 3 and Table 1 also show that there was no clear relationship between the mol.wt and the amount of Lkt protein in the culture supernate, as judged by immunoblotting, and leukotoxic activity. The culture supernate samples in lanes $1,5,6$ and 7 were highly toxic in the $\mathrm{CL}$ assay, that in lane 4 was moderately toxic whereas those in lanes 2, 3 and 8 had low toxicity but appeared to contain as much Lkt protein as the more toxic samples. This was confirmed by ELISA (Table 2). For example, the sample from isolate $\mathrm{Ph} 42$ contained more of the $105 \mathrm{kDa} \mathrm{Lkt}$ protein than strain $\mathrm{Ph} \mathrm{2}$, as determined by ELISA

Table 2. Measurement of Lkt by ELISA

\begin{tabular}{|c|c|c|c|}
\hline \multirow{2}{*}{$\begin{array}{l}\text { Lkt preparation } \\
\text { from strain } \\
\text { no. }\end{array}$} & \multirow{2}{*}{$\begin{array}{c}\text { Amount of } \\
\text { Lkt antigen } \\
\text { (ELISA units } / \mathrm{ml} \text { ) }\end{array}$} & \multicolumn{2}{|c|}{$\begin{array}{l}\text { Lkt activity: percentage } \\
\text { inhibition of CL response } \\
\text { of neutrophils }\end{array}$} \\
\hline & & Bovine & Ovine \\
\hline $\mathrm{Ph} 2$ & 100 & 97 & 97 \\
\hline $\mathrm{Ph} 42$ & 150 & 6 & 26 \\
\hline $\mathrm{Ph} 14$ & 84 & 6 & 20 \\
\hline FA 1 & 74 & 78 & 85 \\
\hline 10634 & 81 & 95 & 95 \\
\hline UT 3 & $<10$ & 100 & 100 \\
\hline UT 23 & 12 & 30 & 39 \\
\hline
\end{tabular}

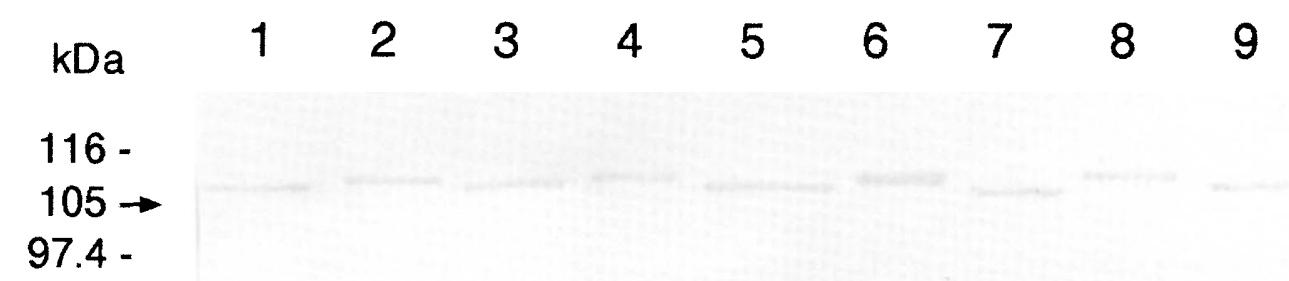

$66-$

Fig. 3. Differences in mol. wt of Lkt proteins of $P$. haemolytica strains. Culture supernates from different strains, grown to late $\log$ phase in BHIB, were subjected to SDS-PAGE and immunoblotting with a MAb to Lkt. Lane 1, strain Ph 2; 2. Ph 42; 3, Ph 14; 4, Ph 44; 5, FA 1; 6, 10634; 7, UT 3; 8, UT 23; 9, UT 2. Positions of mol. wt markers are shown on the left. 
(150 and 100 Units of Lkt antigen $/ \mathrm{ml}$, respectively) but the former had little leukotoxic activity on bovine and ovine neutrophils, whereas the latter was highly toxic. However, there were some discrepancies between the amounts of Lkt antigen detected by immunoblotting and by ELISA, as seen with the UT 3 and UT 23 preparations. Bands are clearly visible in the immunoblots (Fig. 3, lanes 7 and 8, respectively) and yet little antigen was detected by ELISA.

\section{Discussion}

The present study was designed to investigate whether different strains of $P$. haemolytica, used previously in this laboratory and which showed variation in LPS and OMP profiles $[13,14]$, produced different amounts of Lkt activity. To compare Lkt production by different strains, it was first necessary to standardise the growth and sampling conditions, as various factors such as temperature, $\mathrm{pH}$, composition of growth medium, growth rate and time of harvest have been reported to influence Lkt activity $[23,24]$. Lkt has been shown to be produced by actively growing cells and the level of toxicity in the culture supernate peaks at the end of $\log$ phase or earlier, depending on the growth medium $[25,26]$. In the present study, with BHIB as the growth medium, growth rates varied from strain to strain but all strains produced maximum toxin activity at the end of log phase and thereafter the activity declined. Loss of activity in the ageing cultures was accompanied by the appearance of immunoreactive material of lower mol. wt than the usual $105-\mathrm{kDa}$ form, as reported by Chang et al. [7], but the samples taken at the end of $\log$ phase also lost activity on standing and on prolonged storage. For these reasons, it was important to standardise the time of harvest of culture supernates and to assay toxin activity promptly.

Strains representative of serotypes $1-12$ of $P$. haemolytica have been shown to produce leukotoxin activity, although some were reported to have only low toxicity [27-30]. Some untypable strains were found not to produce Lkt, but these were isolated from chickens rather than ruminants and so their identity may be in doubt [28]. In the present study, representatives of most of the 16 recognised serotypes and four bovine untypable strains were found to produce leukotoxic activity against bovine and ovine neutrophils. Of the 33 strains tested, most (24) were highly or moderately toxic. All four of the biotype $\mathrm{T}(P$. trehalosi) strains had low toxicity, as did one serotype A1, two A2 and one untypable strain. The low toxicity of a T3 strain has been reported previously [31]. In the present panel of strains, nine A1 and five A2 strains were tested and both of these serotypes contained high, moderate and low toxin producers. This inter-strain variation within the serotype groupings parallels the variation in OMP and LPS profiles in a similar panel of $P$. haemolytica strains [13-15]. Only one strain, $\mathrm{Ph} \mathrm{6}$, produced no detectable toxic activity, although Southern blot analysis showed that it contained the $l k t$ genetic determinant (data not shown). This strain is serotype A1 but is atypical in other respects such as its biochemical, OMP and LPS profiles [14] and plasmid profile [16].

A surprising finding in the present study was that there was no clear relationship between the amount of Lkt protein in the culture supernate, as judged by immunoblotting and ELISA, and leukotoxic activity in the CL-inhibition assay. For example, the culture supernates from strains $\mathrm{Ph} 14$ and 42 contained the $105-\mathrm{kDa}$ Lkt protein in amounts similar to that from strain $\mathrm{Ph} 2$ but had little leukotoxic activity. Such differences in toxicity of the Lkt preparations might be due to intrinsic differences in the Lkt proteins produced by the various strains or due to strain differences in other Pasteurella products such as the LktC activator protein or LPS. For example, it has been suggested that LPS may have a role in the haemolytic activity of $E$. coli haemolysin [32] and mutations in LPS biosynthesis have been shown to be responsible for reduction in haemolysin activity [33]. There is inter-strain variation in the LPS profiles of our P. haemolytica isolates [13] but there was no obvious correlation between Lkt activity and LPS type. Furthermore, neither smooth nor rough LPS from $P$. haemolytica alone caused any significant inhibition of the CL response of bovine neutrophils but a synergic effect with Lkt cannot be excluded.

Most strains produced Lkt of c. $105 \mathrm{kDa}$ but four strains, (Ph 42, Ph 44, 10634 and UT 23) produced a higher mol.wt (c. $108 \mathrm{kDa}$ ) form. However, there was no obvious relationship between these larger Lkts and their toxic activities or the characteristics of the producing strain (Table 1). Thus, Ph 42 is a bovine A2 isolate from pneumonic lung and its culture supernate had low toxicity; $\mathrm{Ph} 44$ is a bovine A2 strain but from the nasopharynx of a healthy animal and the sample had moderate toxicity; 10634 is an ovine A7 isolate from a pneumonic lung and its culture supernate was highly toxic and a bold Lkt band was evident in the immunoblot; and UT 23 is an untypable bovine lung isolate and had low toxicity.

Differences in mol.wt and toxicity of the leukotoxins from different serotypes have been reported previously although in most studies only a single strain of each serotype was examined [29, 30, 34, 35]. Lkt produced by a serotype $\mathrm{T} 3$ strain was significantly less toxic for bovine leucocytes than Lkt from serotype Al and had a slightly higher mol.wt [31]. Recently, Burrows et al. [35] showed by SDS-PAGE and immunoblotting that reference strains of all 16 serotypes produced Lkt proteins that were antigenically related and had similar, but not identical, mol.wts. Other workers have demonstrated some antigenic differences in the Lkt proteins from certain serotypes by antibody 
neutralisation tests $[27,30]$ and genetic differences in the lkt determinants have been revealed by Southern blotting with the serotype $1 \mathrm{lkt}$ determinant as a probe [35]. In this laboratory, Southern blot analysis of selected strains with a probe incorporating the serotype-1 lkt determinant revealed restriction fragment length polymorphisms between different strains even within the same serotype (unpublished data). Antigenic differences in the leukotoxin proteins could account for the apparent discrepancies between the amounts of some of the Lkt antigens detected by immunoblotting and by ELISA. With preparations from strains UT 3 and UT 23, for example, bands were clearly visible in the immunoblots and yet little antigen was detected by ELISA. This may relate to the fact that the ELISA system used here depended on the interaction of two antibodies with the toxin, neither of which was homologous, although both antibodies gave similar results in immunoblotting.

These data, taken together with our previous findings showing differences in LPS, OMP and plasmid profiles, even within a given serotype, reveal considerable heterogeneity in $P$. haemolytica isolates. Further analysis of the lkt genetic determinants of these strains may reveal that different genes coding for distinct leukotoxin proteins may exist within $P$. haemolytica, as has been found in Actinobacillus pleuropneumoniae [36]. Attempts to correlate these differences with virulence of the strains may prove useful in epidemiological studies.

We thank Dr G. D. Westrop for the supply of recombinant leukotoxin, Dr R. L. Davies for purified LPS and Dr W. Donachie for $P$. haemolytica strains, MAb and typing sera. The work was supported in part by the Human Frontier Science Program.

\section{References}

1. Frank GH. Pasteurellosis of cattle. In: Adlam C, Rutter JM (eds) Pasteurella and pasteurellosis. London, Academic Press. 1989: 197-222.

2. Gilmour NJL, Gilmour JS. Pasteurellosis of sheep. In: Adlam C, Rutter JM (eds) Pasteurella and pasteurellosis. London, Academic Press. 1989: 223-262.

3. Sneath PH, Stevens M. Actinobacillus rossii sp. nov., Actinobacillus seminis sp. nov., nom. rev., Pasteurella bettii sp. nov., Pasteurella lymphangitidis sp. nov., Pasteurella mairi sp. nov., and Pasteurella trehalosi sp. nov. Int J Syst Bacteriol 1990; 40: 148-153.

4. Confer AW. Immunogens of Pasteurella. Vet Microbiol 1993; 37: $353-368$

5. Conlon JA, Shewen PE, Lo RYC. Efficacy of recombinant leukotoxin in protection against pneumonia challenge with live Pasteurella haemolvtica A1. Infect Immun 1991; 59: 587-591.

6. Coote JG. The RTX toxins of Gram-negative bacterial pathogens: modulators of the host immune system. Rev Med Microbiol 1996; 7: 53-62.

7. Chang Y-F, Young R, Post D, Struck DK. Identification and characterization of the Pasteurella haemolytica leukotoxin. Infect Immun 1987; 55: 2348-2354.

8. Lo RYC, Strathdee CA, Shewen PE. Nucleotide sequence of the leukotoxin genes of Pasteurella haemolytica A1. Infect Immun 1987; 55: 1987-1996.

9. Shewen PE, Wilkie BN. Cytotoxin of Pasteurella haemolytica acting on bovine leukocytes. Infect Immun 1982; 35: 91-94.
10. Maheswaran SK, Kannan MS, Weiss DJ et al. Enhancement of neutrophil-mediated injury to bovine pulmonary endothelial cells by Pasteurella haemolytica leukotoxin. Infect Immun 1993; 61: 2618-2625.

11. Chang YF, Renshaw HW. Pasteurella haemolytica leukotoxin: comparison of ${ }^{51}$ chromium-release, trypan blue dye exclusion, and luminol-dependent chemiluminescence-inhibition assays for sensitivity in detecting leukotoxin activity. Am J Vet Res 1986; 47: $134-138$

12. Czuprynski CJ, Noel EJ. Influence of Pasteurella haemolytica Al crude leukotoxin on bovine neutrophil chemiluminescence Infect Immun 1990; 58: 1485-1487.

13. Ali Q, Davies RL, Parton R, Coote JG, Gibbs HA. Lipopolysaccharide heterogeneity in Pasteurella haemolytica isolates from cattle and sheep. J Gen Microbiol 1992; 138: 2185-2195.

14. Ali Q. Characterisation of virulence-related properties of Pasteurella haemolytica isolates. PhD Thesis 1992; Glasgow University.

15. McCluskey J, Gibbs HA, Davies RL. Variation in outermembrane protein and lipopolysaccharide profiles of Pasteurella haemolytica isolates of serotypes A1 and A2 obtained from pneumonic and healthy cattle. Microbiology 1994; 140: $807-814$

16. Azad AK, Coote JG, Parton R. Distinct plasmid profiles of Pasteurella haemolytica serotypes and the characterization and amplification in Escherichia coli of ampicillin-resistance plasmids encoding ROB-1 $\beta$-lactamase. $J$ Gen Microbiol 1992; 138: 1185-1196.

17. Davies RL, Ali Q, Parton R, Coote JG, Gibbs HA, Freer JH. Optimal conditions for the analysis of Pasteurella haemolytica lipopolysaccharide by sodium dodecyl sulphate-polyacrylamide gel electrophoresis. FEMS Microbiol Lett 1991; 90: 23-28.

18. Davies RL, Parton R, Coote JG, Gibbs HA, Freer JH. Outermembrane protein and lipopolysaccharide variation in Pasteurella haemolytica serotype Al under different growth conditions. J Gen Microbiol 1992; 138: 909-922.

19. Shreeve BJ, Biberstein EL, Thompson DA. Variation in carrier rates of Pasteurella haemolytica in sheep. II. Diseased flocks. $J$ Comp Pathol 1972; 82: 111-118.

20. Laemmli UK, Cleavage of structural proteins during the assembly of the head of bacteriophage T4. Nature 1970; 227: $680-685$.

21. Towbin H, Staehelin T, Gordon J. Electrophoretic transfer of proteins from polyacrylamide gels to nitrocellulose sheets: procedure and some applications. Proc Natl Acad Sci USA 1979; 76: 4350-4354.

22. Bradford MM. A rapid and sensitive method for the quantitation of microgram quantities of protein, utilizing the principle of protein-dye binding. Anal Biochem 1976; 72: $248-257$.

23. Strathdee CA, Lo RYC. Regulation of expression of the Pasteurella haemolytica leukotoxin determinant. $J$ Bacteriol 1989; 171: 5955-5962.

24. Gatewood DM, Fenwick BW, Chengappa MM. Growthcondition dependent expression of Pasteurella haemolytica A1 outer membrane proteins, capsule, and leukotoxin. Vet Microbiol 1994; 41: 221-233.

25. Shewen PE, Wilkie BN. Evidence for the Pasteurella haemolytica cytotoxin as a product of actively growing bacteria. Am J Vet Res 1985; 46: 1212-1214.

26. Confer AW, Durham JA. Sequential development of antigens and toxins of Pasteurella haemolytica serotype 1 grown in cell culture medium. Am J Vet Res 1992; 53: 646-652.

27. Shewen PE, Wilkie BN. Pasteurella haemolytica cytotoxin: production by recognized serotypes and neutralization by typespecific rabbit antisera. Am $J$ Vet Res 1983; 44: 715-718.

28. Chang YF, Renshaw HW, Young R. Pneumonic pasteurellosis: examination of typable and untypable Pasteurella haemolytica strains for leukotoxin production, plasmid content, and antimicrobial susceptibility. Am J Vet Res 1987; 48: 378-384.

29. Gentry MJ, Confer AW, Holland SG. Comparison of the toxic and antigenic properties of single bovine isolates of Pasteurella haemolytica representing five serotypes and an untypable strain. Vet Microbiol 1988; 16: $351-367$.

30. Gerbig DG, Cameron MR, Struck DK, Moore RN. Characterization of a neutralizing monoclonal antibody to Pasteurella haemolytica leukotoxin. Infect Immun 1992; 60: 1734-1739.

31. Winfield EO, Lo RYC. Analysis of the Pasteurella haemolytica 
T3 leukotoxin determinant. Abstracts of the General Meeting of the American Society for Microbiology, Dallas, Texas, 1991: 33.

32. Welch RA. Holistic perspective on the Escherichia coli hemolysin. In: Miller VL, Kaper JB, Portnoy DA, Isberg RR (eds) Molecular genetics of bacterial pathogenesis. A tribute to Stanley Falkow. Washington DC, ASM Press. 1994: 351-364.

33. Stanley PLD, Diaz P, Bailey MJA, Gygi D, Juarez A, Hughes C. Loss of activity in the secreted form of Escherichia coli haemolysin caused by an rfaP lesion in core lipopolysaccharide assembly. Mol Microbiol 1993; 10: 781-787.
34. Lo RYC. Molecular characterisation of the leukotoxin determinants of Pasteurella haemolytica serotypes 1-12. Annual Meeting of The American Society for Microbiology, Miami, Florida, 1988. Abstract B-60.

35. Burrows LL, Olah-Winfield E, Lo RYC. Molecular analysis of the leukotoxin determinants from Pasteurella haemolytica serotypes 1 to 16. Infect Immun 1993; 61: 5001-5007.

36. Frey J, Bosse JT, Chang Y-F et al. Actinobacillus pleuropneumoniae RTX toxins: uniform designation of haemolysins, cytolysins, pleurotoxin and their genes. $J$ Gen Microbiol 1993; 139: 1723-1728. 